\title{
基于人本主义的城市发展理论探讨
}

栾阿诗

盐城师范学院公共管理学院

DOI:10.32629/mef.v1i2.18

[摘 要] 本文在搜集资料的基础上, 以时间为序, 对人本主义的城市发展理论进行了总结,并着重对现代的城市规划思想进行 了介绍,试图梳理人本主义思想的发展脉络及其对于城市发展的影响,以期为当代国内城市规划提供借鉴。

[关键词] 人本主义; 城市规划; 以人为本; 设计

随着经济社会的快速发展, 城市聚落发展迅速, 在城市 形成以及发展过程中逐渐形成了城市规划的思想理论, 并且 不断发展成熟。通过对城市规划学科发展的整个历史进行了 解发现, 城市规划的整体发展史、城市规划思想的不断演进 其实就是 “人本主义” 和 “非人本主义” 两者之间交替、徘 徊进行的一步历史。城市规划中的人本思想不再是新鲜的事 物, 越来越多的规划师和学者顺应了时代的发展和社会的需 要, “以人为本” 的规划思想在各项规划法规和项目书中都 有所体现, 但是人本主义不是一个新生的概念, 本文试图从 梳理中西方人本化规划思想的理论入手, 分析人本主义思想 对于城市发展的影响。

\section{1 人本主义的内涵及其对城市规划的影响}

(1) 人本主义的源起及其内涵

人本主义思想发轫于古希腊时期的理性主义思想传统, 到了文艺复兴时期, 西方资产阶级革命的先驱提出了 “天赋 人权、平等、自由、博爱” 等人本主义理念, 人本主义思想 得到了进一步的发展, 形成了一种比较系统的思想形态。人 本主义强调人的至上性, 认为人是自然界的唯一主体, 主要 目的是明确以人为本思想的重要地位, 也就是一切从人的利 益与权利为根本出发点, 将此作为至关重要的地位。各个阶 段的人本主义虽然表现形式不同, 但都围绕人的理性和非理 性展开, 倡导一种人本精神。在城市设计的价值观的发展过 程中, 从来没有脱离过对于人本主义的探讨。

“以人为本” 的城市发展思想, 指的是城市发展过程中 充分满足和考虑人的精神和物质需求、积极推动人的身心健 康的更好更快的发展, 所有居民都可以享受自由、平等的权 利以及安全、轻松的工作生活环境。

(2) 古代城市规划思想

古希腊时期, 人本主义对人类社会的普遍关怀在城市建 设中得到了体现, 庙宇遍布希腊各地, 人们不仅在庙宇中举办 各种宗教活动, 而且还通过庙宇举行各种活动。关于城市的定 义: 城市是为美好生活而维持很小规模的一个社区。从社区 范围和规模方面进行分析, 应该使居民既能自由又有节制的 享受安全舒适的生活。使得城市具有一体化特征, 是人们追求 正义以及共同的目标, 朝着幸福美满的生活而努力的目标。

古罗马时期, 人本主义观念因不符合时代精神逐渐被实
用主义所取代, 在此阶段, 城市发展的应用理性特征更加显 著, 城市规划的实用性更强。

我国古代城市发展可追溯到夏商周时期, 商代开始出现 城市的雏形, 中国从古代开始就出现 “天人合一” 等诸多哲 学思想, 从中就可以看出是人本主义思想的萌芽, 在具体应 用城市规划时充当的只是一种价值观, 并且通过 “王城居中” 等城市形态即可体现出古代城市规划中权力至上的以帝王 为中心的思想。

（3）中世纪前后的城市规划思想

中世纪相当长的一段时期, 城市兴起并大规模发展, 市民 们按照自身意愿及社会需求形成了新的生活观念, 在社会各 个领域产生了人本主义思潮。而这些包含市民各项需求的思 潮也就成为了城市不断向前发展的动力。这一时期的城市规 划尊重了城市的发展规律, 人的活动大大丰富, 充分体现了人 的尺度。所以, 中世纪在城市规划上体现出人类价值理性与非 理性的叠合, 规划功能被弱化, 充分体现了人本主义思想。

在文艺复兴时期, 规划思潮深深影响了西方国家的城市 规划理念, 在理想形态影响下, 学者提出了各种理想的城市 形态, 城建活动也打破了宗教束缚, 建设了诸多精致、完美、 生机无限的城市, 如佛罗伦萨、威尼斯等。

在我国封建时期, 虽然受到王权主义、儒家思想影响, 但伴随手工业不断发展, 城市逐渐兴起了集市。进行城市规 划时也更加重视多数市民的生活、社会需求, 在一定程度上 也体现出人本主义思想。

\section{(4) 现代城市规划思想}

现代城市的发展理念演进经历了开端-发展一反思一再发 展的阶段, 具体可分为: 理想主义时期一功能主义时期一人 本主义思潮时期一可持续发展时期。以下以时间为序梳理城 市规划的几个重要理论及其人本主义思想体现:

1898 年, 霍华德的田园城市理论指出, 工业化条件下城市 不能给人类提供适宜的居住, 强调 “城市应该与乡村结合”;

盖迪斯在霍华德之后经过一系列研究分析后提出区域 规划理论, 在其《进化中的城市》和《城市发展》著作中, 可以很好的反映出人本主义的规划思想, 此种思想已经超越 了城市的界限分析区域的经济背景以及聚落的模式, 基于自 然地域从而进行更为合理的规划。 
20 世纪 30 年代, “邻里单位” 的城市规划思想考虑到 老弱儿童穿越道路的危险性, 按照设置小学的标准控制 “邻 里单位”的人口及用地规模;

1933 年, 《雅典宪章》提出城市应按照全市人民的意志 进行规划, 应该按照人的尺度来估量城市各部分的大小范围, 规划师在工作中要以人为本, 确立了现在城市规划的人本主 义思想;

在上世纪五十年代, 伴随经济、科技迅猛发展, 现代主义 大行其道, 城市规模飞速扩张, 但这个过程中也逐渐加剧了社 会矛盾, 城市环境不断恶化, 人们对城市空间的改造意愿也越 来越强烈, 希望能够显著改善生活与工作环境。当功能主义失 败, 人们更加重视原始需求, 人本主义逐渐替代了功能主义。 但由于人类的需求非常复杂, 因此, 人本主义强调多样化的城 市与社区。该时期, 规划思想中人本关怀替代了功能物化。

1961 年, 简 - 雅各布发表了《美国大城市的死与生》, 对规划界一直奉行的最高原则进行了批判, 她认为: “多样性 是城市的天性”, 而 20 世纪 $50^{\sim} 70$ 年代由美国专家主导、联 邦政府大量投资的空前绝后的城市内城改建、高速公路兴建 等行为 “不是城市的改建, 而是对城市的洗劫”。城市是由人 类聚居而形成的产物, 城市容纳了大量居民, 这些居民的需 求、能力、兴趣等都有所不同。所以, 城市不可能变成艺术 品, 可以说艺术是生活经过抽象而形成的一种技艺, 但城市 是复杂、积极、生动的具体生活, 充分体现了人本主义思想。

1977 年, 《马丘比丘宪章》指出人和自然环境的和谐发 展, 强调人和人的相互关系对于城市和城市规划的重要性, 展现了人本主义的理性化成果;

20 世纪 80 年代, 新城市主义提出, 社区路网采用方格状, 而且还需要将步行系统考虑在内, 城市规划必须代表城市居 民的切身利益, 在进行城市规划时也需要听取来自公众的建 议与意见。

在 1998 年, 北京宪章明确提出技术必须以人为核心, 扩 展了人本主义的概念, 把人和环境看做一个整体。

20 世纪 80 年代后期, 城市规划与社会规划开始不断融 合, 例如日本学者深入研究了老年人的公共服务设施, 主要 是为了更好地解决老龄化问题, 但该手段被当作城市规划。

通过对现代城市规划思想理论的分析总结, 我们发现。 人本主义始终是贯穿城市发展的一条思维主线, 这其中不乏 不同思想观念, 在不同思维方式与价值认识的协调与冲突下, 城市规划学飞速发展。反观当代中国的城市发展, 高速度的 城市化引发的一些问题也让现代城市规划的许多学者开始 反思并探求一种 “以人为本” 的城市建设模式。

\section{2 结束语}

回顾城市发展及城市规划学科的历史, 我们发现, 无论 科技如何发展, 人本主义的思潮始终影响着城市的设计与发 展。尤其是在现代城市规划的人本主义时期, 学者深刻认识 到城市结构、经济社会结构的多样化与复杂化, 多门学科如 社会科学逐渐运用于城市规划工作中, 无论是城市规划的设 计还是实践层面, 学者们都更加强调多样性和复杂性是人类 的天性, 强调公众参与。

要让一个城市的发展体现人文关怀, 规划师的作用虽然 不可估量, 我们普通市民也不能坐享其成。人本主义的城市 规划强调公众参与, 我们在参与问卷调查等活动中, 要认真 对待, 提出自己的意见与建议。随着信息时代的到来, 我们有 理由相信, 新技术的支持及城市规划本身的需要将使“人本” 得到发展, “城市让生活更美好” 是一种正在实现的理念而 不只是一种美好愿景。

\section{[参考文献]}

[1]张京祥.西方城市规划思想史纲. [ M ]. 南京.东南大学 出版社,2005,(5):299.

[2]章玉全.基于人本主义思想的规划思考[J].科技经济 市场,2011,(04).95-96.

[3]宁越敏.上海城市持续发展与地域空间结构优化研究 [J].城市规划汇刊, 1998,(02):17-21+34-64.

[4]洪亮平.城市设计历程. [ M ]. 北京: 中国建筑工业出版 社,2002,(12):181.

[5]李月.刘易斯 - 芒福德的城市史观 [D].上海师范大 学,2016,(8):169.

[6]倪世光.西欧中世纪人本思潮的产生及其表现 [J].东 北师范大学学报(哲学社会科学版),1994,(1):36- 40.

[7]朱东风.城市规划思想发展及技术方法走向研究 [J]. 国外城市规划,2004,(02):57-59.

[8]王中. 让人本主义在现代城市规划中闪光一一中西方 人本主义规划思想对现代城市规划的影响[J]. 北京规划建 设,2007,(02):111-113.

[9]王中.城市规划的三位人本主义大师一霍华德、盖迪 斯、芒福德[J].建筑设计管理,2007,(04):41-43.

\section{作者简介:}

栾阿诗(1990--), 女, 汉族, 江苏射阳人, 硕士, 助教, 研究方 向: 学生党建,思想政治教育。

\section{基金项目:}

本文系 2017 年度江苏高校哲学社会科学研究基金项目 研究成果(2017SJBFDY802)。 